\title{
Synergetic role of nanoparticles and micro-scale short carbon fibers on the mechanical profiles of epoxy resin
}

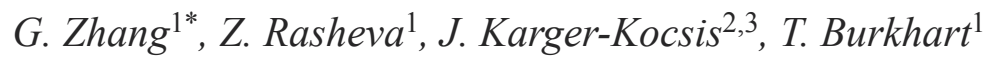 \\ ${ }^{1}$ Institute for Composite Materials, University of Kaiserslautern, 67663 Kaiserslautern, Germany \\ ${ }^{2}$ Department of Polymer Technology, Faculty of Engineering and Built Environment, Tshwane University of Technology, \\ Pretoria 0001, Republic of South Africa \\ ${ }^{3}$ Department of Polymer Engineering, Faculty of Mechanical Engineering, Budapest University of Technology and \\ Economics, H-1111 Budapest, Hungary
}

Received 8 February 2011; accepted in revised form 11 April 2011

\begin{abstract}
It was demonstrated in our previous work that the combined carbon nanofibers (CNFs) and microsized short carbon fibers (SCFs) in epoxy (EP) leads to significant improvements in the mechanical properties of the matrix. In this work, the effect of nano- $\mathrm{SiO}_{2}$ particles, having an extremely different aspect ratio from $\mathrm{CNFs}$, on the tensile property and fracture toughness of SCFs-filled EP was studied. It was revealed that the combined use of SCFs and silica nanoparticles exerts a synergetic effect on the mechanical and fracture properties of EP. Application of SCFs and the nanoparticles is an effective way to greatly enhance the modulus, strength and fracture toughness of the EP simultaneously. The synergetic role of the multiscale fillers was explained by prominent changes in the stress state near the microsized fillers and the plastic zone ahead of the crack tip. The synergetic role of multiscale fillers is expected to open up new opportunities to formulate highperformance EP composites.
\end{abstract}

Keywords: nanocomposites, epoxy, fracture toughness, mechanical properties, short carbon fibers

\section{Introduction}

Epoxy resins (EPs) are nowadays being extensively utilized in engineering applications such as aerospace, automotive, sport and electronic device due to their good mechanical properties and ease in processing. It is a continually challenging task for polymer scientists and engineers to improve the fracture toughness of EP simultaneously with other mechanical properties, e.g. stiffness and strength. Various methods were developed in the last four decades to toughen EPs. Thermoplastic fibers significantly toughen brittle epoxy resin [1]. Microsized rubber particles [2-4], thermoplastic particles $[5,6]$, inorganic particles [7-10] were also proven to toughen EP systems. Rubber particles are effective toughening agents in thermosets because they trigger the localized shear yielding in the related matrices. However, rubber toughening is accompanied with obvious reductions of the modulus and creep resistance of the matrix. Thermoplastic particles can improve the toughness of EP with slight sacrifices of modulus and yield stress [6]. Microsized short fibers (diameter and length in micron scale), e.g. short carbon fibers [11, 12] (SCFs) and short glass fibers [13-16] were also employed to enhance the toughness of polymers. Inorganic particles and short fibers are especially attractive in EP matrices because they can improve the fracture toughness and the modulus (stiffness) at the same time. The toughening mechanism of rigid microparticles may comprise a combination of crack deflection, crack pinning, particle debonding and micro-

\footnotetext{
${ }^{*}$ Corresponding author, e-mail: ga.zhang@ivw.uni-kl.de
} (c) BME-PT 
shear banding of matrix [8, 9, 17-22]. Compared with rigid particles, the toughening mechanisms achieved by short fibers, especially for randomly distributed fibers with a high aspect-ratio, are more complicated. Due to the relatively high aspect-ratio of short fibers, pull-out and fracture of fibers are important contributions to the toughness response [13-16].

Even though microsized fillers can effectively stiffen and toughen the EP matrix, when it is under stress, stress concentration can occur locally near the fillers and induce critical failure of the composite system [21]. In case of microsized short fibers, it should be taken into account that intensive stress concentration occurs at the fiber ends and this can promote fiber slip and may also cause some loss in strength $[13,23]$. Thus, in many cases, the ductility of the matrix, being reinforced with microsized rigid fillers or randomly oriented fibers can be markedly reduced and the strength can only be moderately enhanced or it is even reduced.

In the last two decades, polymer nanocomposites gained intensive interest because of the exceptionally large specific area of the nanofillers available for interaction with the polymer matrix. Inorganic nanoparticles are one kind of common nanofillers being investigated for toughening of polymer matrices. Unlike microsized inorganic particles, inorganic nanoparticles will not lead to significant stress concentration due to their much smaller size which guarantees a good integration with the matrix [21]. It was reported that nanoparticles can simultaneously improve the stiffness, strength and toughness of EPs [21, 24, 25]. In addition, nanoparticles may toughen EP even at a very low loading [25, 26]. The debonding of nanoparticles [21, 25, 27, $28]$ and plastic void growth [25, 28], shear yielding of matrix $[21,27]$ are believed to be the main factors of toughening mechanisms.

In many cases only EP nanocomposites filled with nanoparticles at low concentrations are of practical interests because the introduction of nanofillers at high concentrations will complicate the manufacture process and lead to high costs, as well. From the point of view of the mechanical performance, nanocomposites do not necessarily present superior properties to microcomposites. Adachi et al. [10] compared the $E$-moduli of EP composites reinforced with spherical micro- and nano-silica parti- cles. The contents of the fillers varied from 5 to 35 vol\%. They did not find a significant effect of the particles size on the $E$-modulus, which was still controlled by the volume fraction. Wetzel et al. [21] found that the stiffening effect of large rod-like $\mathrm{CaSiO}_{3}$ particles on EP is stronger than that of the alumina nanoparticles. The $\mathrm{CaSiO}_{3}$ particles have a diameter of 3-5 $\mu \mathrm{m}$ and length to width (aspect) ratio of 3-4. Even though exceptionally good filler/ matrix interaction exists in EP nanocomposites, the nanoparticles constrain the matrix deformation less than microparticles because the former, being in nearly molecular dimensions, are better integrated into the polymer microstructure [21]. Indeed, many research works proved that with low-loading nanoparticles, the modulus of the high-performance epoxy matrix can only be moderately increased [2427]. A direct comparison of the mechanical properties of EP micro- and nanocomposites will supply engineers with a solid knowledge for selecting appropriate materials according to the needs of real applications.

Recent studies $[29,30]$ indicated that the inclusion of nanoparticles much improves the mechanical properties [29] and fatigue life [30] of continuous glass fibers reinforced EPs (GFRP). It was also revealed that to integrate low-loadings CNT into continuous glass fibers (GFRP) [31] and continuous carbon fibers $[32,33]$ reinforced EP (CFRP) significantly improves the mechanical and fracture properties, compared to conventional composites. Even though the mechanisms are still unclear, it was noticed that nanofillers seem to enhance the fibers/ matrix adhesion [31-33]. These pioneer works give hints to enhance the mechanical properties of conventional EP composites reinforced with microsized (non-continuous) fillers by adding low-loading nanofillers.

Indeed, it might be of great interests to combine the advantages of micro- and nanofillers. This may be a promising composite formulation route to combine microfillers at medium to high concentrations, and nanofillers at low concentrations into polymer matrices. It was revealed in our previous work that combined use of SCFs and carbon nanofibers (CNFs) in EP resin leads to a synergetic role on the mechanical properties of the matrix [34]. The composites filled with combined SCFs and CNFs displays better mechanical properties than the materials rein- 
forced only with SCFs or CNFs. However, a combination of two kinds of nanofillers, e.g. CNFs and nanoparticles, was not associated with synergetic effects [34]. It is assumed that that the common use fillers with distinctly different scale sizes is the key issue for eventual synergism. With this context, it is important to know if nanofillers, having distinctly different ratios from CNFs, will also play synergetic roles with the microsized SCFs. As abovementioned, inorganic nanoparticles are one kind of common nanofillers. In the present work, we studied the effect of nano- $\mathrm{SiO}_{2}$ particles on the mechanical properties of EP composites filled with SCFs. Special attentions were paid to the contributions of the respective SCFs, nanoparticles and their combinations.

\section{Experimental}

\subsection{Materials and preparation}

All materials in the present work were prepared on the basis of a commercially available epoxy resin (DER331 by DOW, USA) with an epoxide equivalent weight 182-192 g/equiv. Cycloaliphatic amine hardener (HY 2954; Huntsman, USA) was used to cure the epoxy materials. Fumed spherical silica nanoparticles (Aerosil R8200) with hexamethyldisilazane modification were supplied by Evonik (Germany). The diameter and the specific surface area of the nanoparticles are respectively about 12 $14 \mathrm{~nm}$ and $160 \mathrm{~m}^{2} / \mathrm{g}$. The nanoparticles were used as-received without any further treatment. Milled polyacrylonitrile (PAN)-based carbon fibers (Tenax ${ }^{\circledR}$ A-385) were supplied by Tenax GmbH (Germany). The diameter and the length of the fibers are respectively $7 \mu \mathrm{m}$ and $40-70 \mu \mathrm{m}$. The SCFs were supplied without sizing treatment and were used as-received. Three series of epoxy composites, i.e. microcomposites filled with SCFs, low-loading nanoparticles-filled nanocomposites, and multiscale composites reinforced with both SCFs and low-loading nanoparticles, were compared in this study. The loading of the silica nanoparticles varied from 0.5 to 5.0 vol\%. Pure EP and SCFs-filled EP (with SCF fractions from 5 to 15 vol\%) served as reference materials. The volume fractions of all the fillers were calculated by considering their weights and (bulk) densities. The densities of pure EP, SCF and $\mathrm{SiO}_{2}$ nanoparticles are $1.14,1.74$ and $2.00 \mathrm{~g} / \mathrm{cm}^{3}$, respectively.
Table 1. Compositions of materials studied

\begin{tabular}{|c|l|c|c|c|}
\hline \multirow{2}{*}{ Series } & $\begin{array}{l}\text { Material } \\
\text { codes }\end{array}$ & $\begin{array}{c}\text { Matrix } \\
\text { [vol\%] }\end{array}$ & $\begin{array}{c}\text { SCF } \\
\text { [vol\%] }\end{array}$ & $\begin{array}{c}\text { Nano-SiO } \\
{[\mathbf{v o l \% ]}}\end{array}$ \\
\hline Pure epoxy & EP & 100 & - & - \\
\hline \multirow{3}{*}{ Microcomposites } & $5 \mathrm{CF}$ & 95 & 5 & - \\
\cline { 2 - 5 } & $10 \mathrm{CF}$ & 90 & 10 & - \\
\cline { 2 - 5 } & $15 \mathrm{CF}$ & 85 & 15 & - \\
\hline \multirow{3}{*}{ Nanocomposites } & $1 \mathrm{Si}$ & 99 & - & 1 \\
\cline { 2 - 5 } & $3 \mathrm{Si}$ & 97 & - & 3 \\
\cline { 2 - 5 } & $5 \mathrm{Si}$ & 95 & - & 5 \\
\hline \multirow{3}{*}{$\begin{array}{l}\text { Multiscale com- } \\
\text { posites }\end{array}$} & $10 \mathrm{CF} 0.5 \mathrm{Si}$ & 89.5 & 10 & 0.5 \\
\cline { 2 - 5 } & $10 \mathrm{CF} 1 \mathrm{Si}$ & 89 & 10 & 1 \\
\cline { 2 - 5 } & $10 \mathrm{CF} 2 \mathrm{Si}$ & 88 & 10 & 2 \\
\cline { 2 - 5 } & $10 \mathrm{CF} 3 \mathrm{Si}$ & 87 & 10 & 3 \\
\hline
\end{tabular}

The nanoparticles adhere to each other due to the inherent Van der Waals force between the particles, resulting in nanoparticle agglomerates. The silica nanoparticles in the EP were dispersed by using a high-energy vacuum dissolver (Dispermat, VMAGetzmann, Germany). At an extremely high rotation speed (5800 rpm) of teeth vested metal disc, the dissolver provides high shear forces to break up the agglomerates in the liquid EP in vacuum, followed by degassing. The SCFs were dispersed in the EP with a moderate rotation speed in order to avoid breakage of the fibers. The multiscale composites were prepared by firstly dispersing, with the extremely high rotation speed, the needed amounts of nano- $\mathrm{SiO}_{2}$ in $\mathrm{EP}$ and by subsequent introduction of the $\mathrm{SCF}$ in the nano- $\mathrm{SiO}_{2} / \mathrm{EP}$ compounds. Afterwards, the compounds were blended with the curing agent HY2954 by stirring for 15 min. Finally the mixture was poured into release agent-coated metallic moulds and cured at $70^{\circ} \mathrm{C}$ for 8 hours, followed by 8 hours at $120^{\circ} \mathrm{C}$.

The detailed compositions of the materials are disclosed in Table 1. For simplification purpose, the composite materials were referenced according to the type and the fraction of the fillers as shown in the left column of Table 1. For example, 10CF1Si refers to the multiscale composite filled with 10 vol\% SCF and 1 vol\% nano- $\mathrm{SiO}_{2}$.

\subsection{Glass transition temperature}

Assessment of the glass transition temperature $\left(T_{\mathrm{g}}\right)$ was necessary as it is known that especially the nanofillers may affect the curing of the EP and this results in slight or prominent changes in the $T_{\mathrm{g}}$ [35]. $T_{\mathrm{g}}$ of the composites were determined by differential scanning calorimetry (DSC) using a DSC821 
apparatus (Mettler-Toledo GmbH, Switzerland). All tests were performed in nitrogen atmosphere with a sample mass of about $20 \mathrm{mg}$. The sample was heated from 20 to $200^{\circ} \mathrm{C}$ at a rate of $10^{\circ} \mathrm{C} / \mathrm{min}$. The $T_{\mathrm{g}} \mathrm{s}$ were assessed by the mid-point of the $T_{\mathrm{g}}$ steps.

\subsection{Tensile tests}

Tensile tests were performed at room temperature $\left(21^{\circ} \mathrm{C}\right.$ ) on a Zwick 1474 (Zwick, Germany) universal testing machine at a constant crosshead speed of $0.5 \mathrm{~mm} / \mathrm{min}$. The measurements followed DIN EN ISO 527 using dumbbell shaped specimens. The specimens having a $4 \mathrm{~mm}$ thickness were machined from the molded plates. The length overall of dumbbell specimens is $75 \mathrm{~mm}$. The length and width of narrow section are 30 and $5 \mathrm{~mm}$, respectively. The displacement of each specimen during tension was accurately measured by an extensometer with an initial extension span of $20 \mathrm{~mm}$. $E$-moduli were calculated with $0.05-0.25 \%$ strain. All presented data corresponds to the average of at least five measurements.

\subsection{Fracture toughness}

The fracture toughness $K_{\mathrm{IC}}$ and the critical energy release rate $G_{\mathrm{IC}}$ was determined by means of compact tension (CT) tests according to the standard ISO 13586 on at least five specimens at a crosshead speed of $0.5 \mathrm{~mm} / \mathrm{min}$. The CT specimens were cured in a metallic mold and then both sides were polished by abrasive papers until all visible marks disappeared. A notch was machined and then sharpened by tapping a fresh razor blade into the material, so that a sufficiently sharp natural crack was initiated. The thickness and the width of specimens were 4 and $30 \mathrm{~mm}$, respectively.

In order to analyze material-failure mechanisms, the fracture surfaces of the tensile and CT test specimens were inspected in a scanning electron microscope (SEM, ZEISS SupraTM 40VP, ZEISS, Germany) after being coated a thin gold layer.

\section{Results and discussion}

\subsection{Glass transition temperature}

Table 2 shows the $T_{\mathrm{g}} \mathrm{s}$ of the composites studied. The SCFs does not significantly influence the $T_{\mathrm{g}}$.
Only a slight decrease in $T_{\mathrm{g}}$, if there is any, is noticed with the addition of SCFs. The effect of nanoparticles on the $T_{\mathrm{g}}$ is non-monotonic and seems to be rather complex. With respect to the nanocomposites, the addition of nanoparticles in the range of 1 to $3 \mathrm{vol} \%$ depresses the $T_{\mathrm{g}}$. Further increase of the loading from 3 to $5 \mathrm{vol} \%$, however, gives rise to the $T_{\mathrm{g}}$. Compared with the microcomposite, i.e. $10 \mathrm{CF}$, the nanoparticles in the multiscale composites slightly arise the $T_{\mathrm{g}}$.

The change in $T_{\mathrm{g}}$ for EP nanocomposites is a controversial issue. Some researchers have found that $T_{\mathrm{g}}$ of nanocomposites increases as a function of the filler-loading [21,36], whereas others observed the opposite [28, 37-41], and again others found nonmonotonic trends $[42,43]$. In general, the restricted mobility of polymer chains in the vicinity of the nanofillers is believed to arise the $T_{\mathrm{g}}[21,35,36,40$, 42]. However, the free volume at the nanofillerresin interface can lower the $T_{\mathrm{g}}[39,40,42]$. Moreover, a possible plasticizing effect of uncured or less cured epoxy resin, caused by the presence of nanoparticles, can lower the $T_{\mathrm{g}}[38,40,41]$. The mechanisms how nanoparticles decrease the crosslink degree of EP is still not clear. Although the kinetically-controlled curing reaction is advancing also in presence of nanofillers, it may become hindered in the diffusion-controlled stage $[35,37]$. Note that selective absorption of the resin or the hardener at the silica surface can lead to an off-stoichiometry in the interphase. This is associated with a marked difference in the cross-link density locally. We assume that the preferential adsorption at the nanoparticles can decrease the $T_{\mathrm{g}}$ due to the lower cross-link density near the filler-matrix interface. If this is the case, such a 'core-shell'-type structure (core:rigid silica, shell: EP with lower cross-linking then the bulk) can promote the cavitation of the nanoparticles and enhance the ductility of the material. The complexity of the underlying chemistry does not allow the reasoning of the observed change in the $T_{\mathrm{g}}$.

\subsection{Tensile properties}

Figure 1a shows representative stress-strain curves of pure EP, nanoparticles-filled EP, SCFs-filled EP

Table 2. $T_{\mathrm{g}} \mathrm{s}$ of materials studied

\begin{tabular}{|l|c|c|c|c|c|c|c|c|c|c|c|}
\hline Material codes & $\mathbf{E P}$ & $\mathbf{5 C F}$ & $\mathbf{1 0 C F}$ & $\mathbf{1 5 C F}$ & $\mathbf{1 S i}$ & $\mathbf{3 S i}$ & $\mathbf{5 S i}$ & $\mathbf{1 0 C F 0 . 5 S i}$ & $\mathbf{1 0 C F} 1 \mathrm{Si}$ & $\mathbf{1 0 C F 2 S i}$ & 10CF3Si \\
\hline$T_{\mathrm{g}} \mathrm{s}\left[{ }^{\circ} \mathrm{C}\right]$ & 133.4 & 131.4 & 130.1 & 130.5 & 129.4 & 128.1 & 136.8 & 133.7 & 131.9 & 130.8 & 130.8 \\
\hline
\end{tabular}


and multiscale-fillers reinforced EP. Pure EP first exhibits a linear stress-strain response (between 0 and $0.3 \%$, approximately) showing an $E$-modulus of about $2.71 \mathrm{GPa}$. The transition from elastic to nonelastic behavior was interpreted in terms of 'strain-softening' due to nonrecoverable deformation with increasing strain $[44,45]$. Figure $1 \mathrm{~b}$ shows
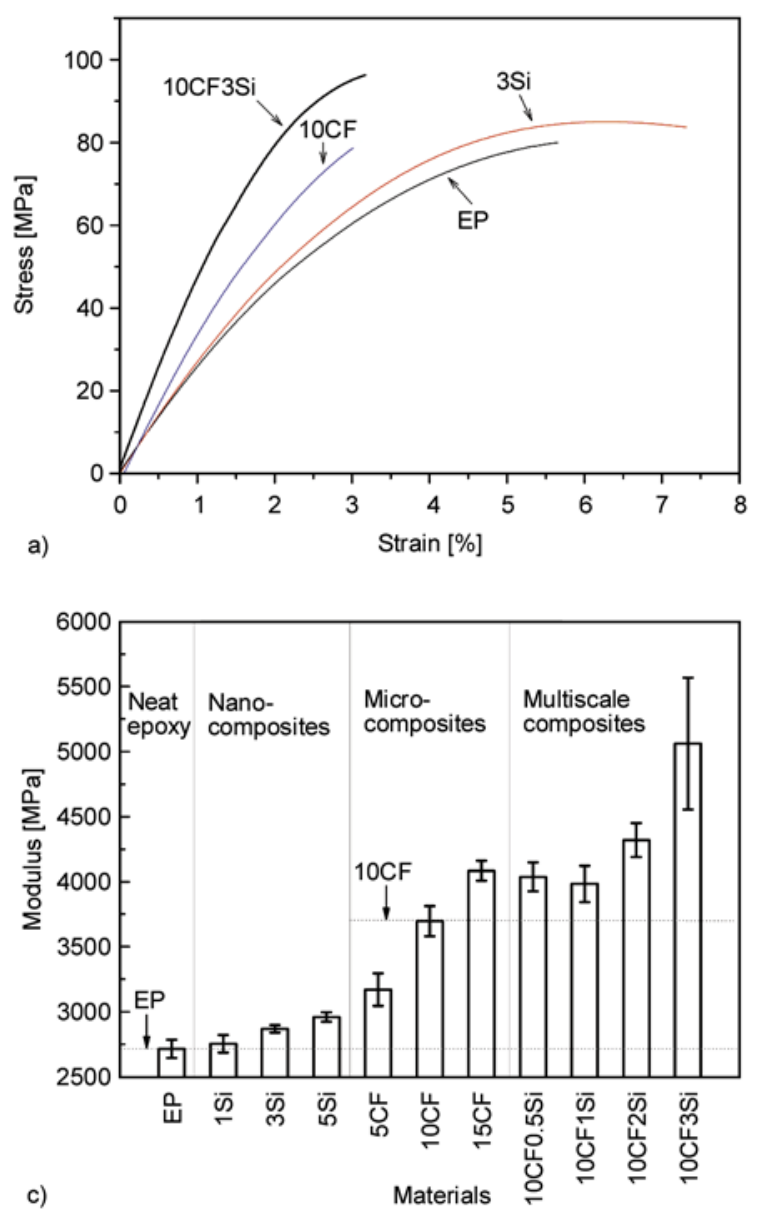

the slopes, defined in [44] secant modulus $E_{\mathrm{sm}}$, of the local points on the curves in Figure 1a as a function of strain. The data with strain from 0 to $0.3 \%$ was not shown due to the scattering of the data. The tendency of the so-called secant might give hints on debonding of fillers from polymer matrix in the loading process [44]. From Figure 1b, at a low strain
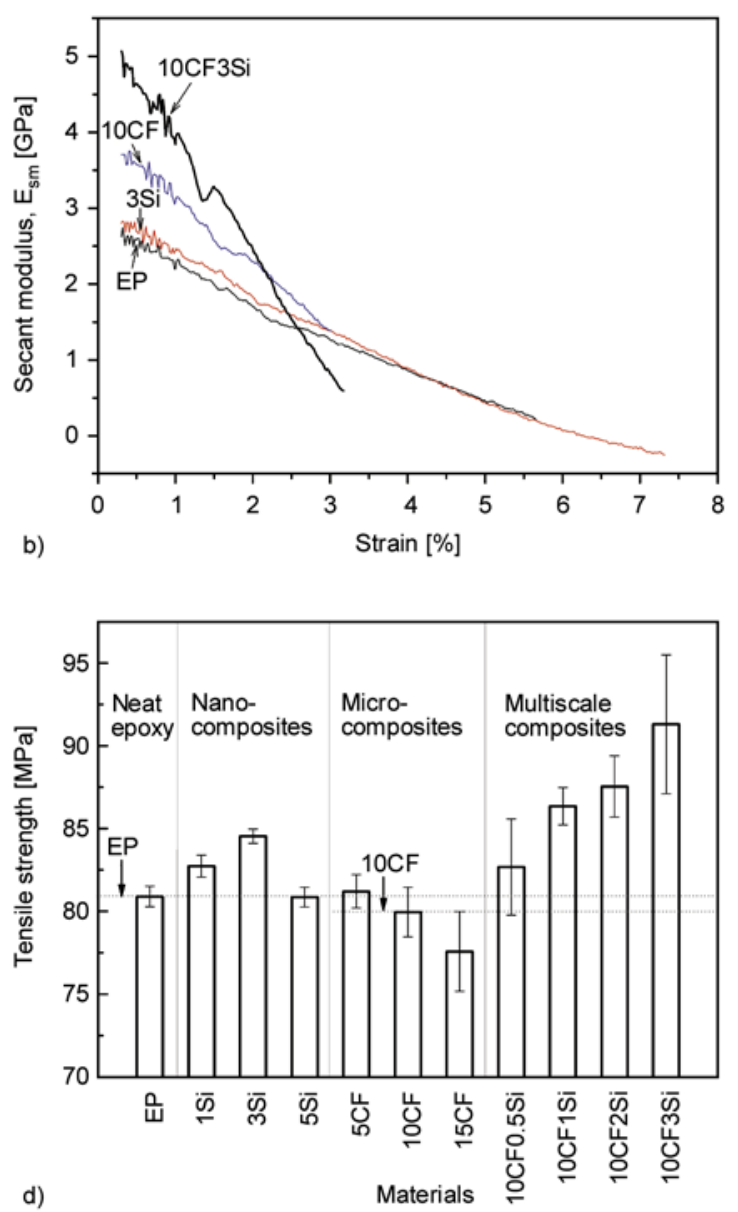

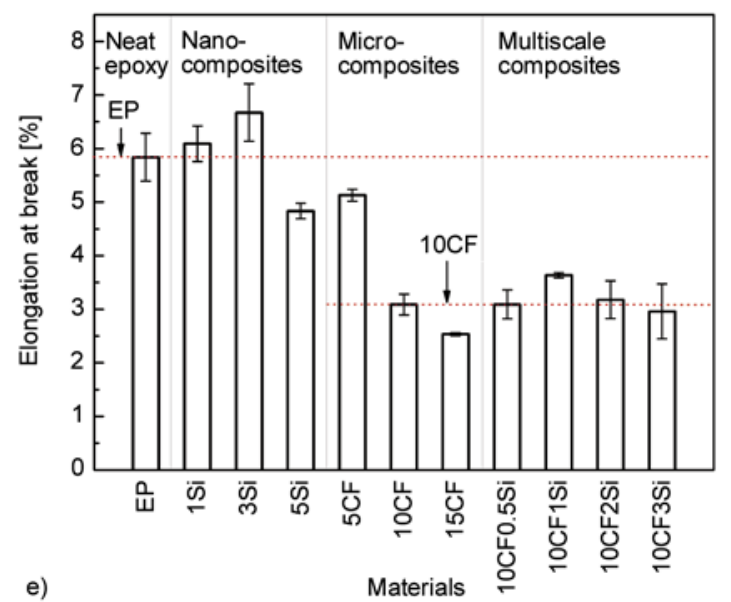

Figure 1. Stress-strain curves of typical materials studied (a), secant moduli of the materials in a (b), and the tensile characteristics: E-modulus (c), tensile strength (d) and elongation rate at break (e) of epoxy composites. Dash lines in (c), (d) and (e) indicating the levels of two reference materials, i.e. pure epoxy and SCFs/EP, are added for easier comparisons. 
the secant modulus of the nanocomposite ( $3 \mathrm{Si})$ is higher than EP. However, when the strain is higher than $\sim 4.5 \%$, the two materials have similar modulus. With respect to the SCF-composite, the secant modulus declines rapidly with increasing the strain due to debonding of SCFs, before critical failures take place. The 'strain-softening' effect of the multiscale composite $\left(10 \mathrm{CF} 3 \mathrm{SiO}_{2}\right)$ is more evident compared to 10CF. The enhanced 'strain-softening' of the multiscale composites compared with the SCF-composite will be discussed below.

The mean values of $E$-moduli, tensile strengths and elongations at break of the materials studied were displayed in Figure 1c-Figure 1e. The low-loading nanoparticles lead to a slight but significant increase in modulus (cf. Figure 1c). The tensile strength of epoxy is moderately increased with nanoparticles varying from 1 to 3 vol\%. (cf. Figure 1d). A further increase of the nanoparticle loading to $5 \mathrm{vol} \%$ leads to a decrease in tensile strength. With a nanoparticle loading less than $3 \mathrm{vol} \%$, the elongation rate is slightly increased. Filled with 5 vol\% nanoparticles, however, the material exhibits a reduced ductility (cf. Figure 1e).

The reinforcing effect of SCFs is more prominent than that of the nanoparticles. Incorporation of 10 vol $\%$ SCF dramatically increases the $E$-modulus of the matrix. The $E$-modulus of the EP linearly increased with increasing the SCF fraction. The effect of randomly distributed SCFs on the strength is more dependent on the fiber-matrix interface than on their alignment $[46,47]$. The incorporated SCFs in the present work do not lead to obvious improvement in tensile strength and even a slight decrease can be noticed if the SCF fraction is higher than 10 vol\% (cf. Figure 1d). So, the constraint matrix deformability and the stress concentrations at the fibers significantly reduce the ductility of the matrix (Figure 1d). Therefore, in spite of the highly improved modulus, the tensile strength remained unaffected or even deteriorated due to the presence of SCFs (cf. Figure 1d).

The combination of the microfillers and the nanofillers leads to impressive improvements in modulus and strength data of the EP (cf. Figure 1c and Figure $1 \mathrm{~d}$ ). The modulus and strength of the multiscale composites increase with increasing the nanoparticle loading. Note that among the systems studied, application of multi-scale fillers was the only way to achieve improvements in modulus and strength at the same time. In addition, it is interesting to note that the enhancements in the modulus and strength owing to the multiscale fillers are significantly higher than the superposition of the separate contributions by respective fillers, as realized in the SCFs-filled and the nanoparticles-filled EP (cf. Figure 1c and Figure 1d). Therefore, the multiscale fillers have synergetic effects on the stiffeness and strength of the EP matrix. The elongation at break values of the multiscale composites are similar to those of the composites filled only with SCFs (cf. Figure 1e).

Figure 2a shows a typical fracture surface of the nanocomposites filled with nanoparticles $(1 \mathrm{Si})$. The crack propagation direction is indicated by an arrow. Numerous dimples can be recognized on the fracture surface (cf. Figure 2a).

With respect to the reinforcing effect of SCFs, according to the modified rule of mixture [48, 49], the stiffening (reinforcing) efficiency depends on the fiber aspect ratio and fiber orientation, as shown in Equations (1) and (2):

$E=\left(\eta E_{\mathrm{f}}-E_{\mathrm{m}}\right) V_{\mathrm{f}}+E_{\mathrm{m}}$

with

$\eta=\eta_{0} \eta_{1}$

where $\eta$ is defined as a stiffening efficiency and $\eta_{0}$ and $\eta_{1}$ respectively the length efficiency factor and the orientation efficiency factor, respectively. $E_{\mathrm{f}}$ and $E_{\mathrm{m}}$ refer to the moduli of the fiber and the matrix, respectively. $V_{\mathrm{f}}$ is the volume fraction of the fibers. According to the linear relationship between the modulus and the volume fraction of SCFs (cf. Figure 1c), the $\eta$ is determined to be about 0.05 for the $\mathrm{EP}+\mathrm{SCF}$ composites. The stiffening efficiency of SCFs in this work agrees well with that achieved in polyethersulphone (PES) and polyphenylene sulphide (PPS) systems reinforced by randomly aligned SCFs [50]. Figure $2 \mathrm{~b}$ and Figure $2 \mathrm{c}$ show representative tensile fracture surfaces of SCFsfilled epoxy (10SCF) with low and high magnifications, respectively. The EP matrix fails in a brittle manner except some ribs formed due to coalesce of cracks in different planes. Figure $2 \mathrm{c}$ displays a typical SCF-matrix interface taken from the fracture surface of $10 \mathrm{CF}$. It is clear that the SCF-matrix interface was strongly involved in the cracking. The 
propagation of local failure at SCF-matrix interface can be hindered by adhering points as indicated by dash-line arrows in Figure 2c.

Figure 2d, 2e and 2f display SEM pictures taken from the tensile fracture surface and SCF-matrix interface, respectively, of the multiscale composite (10CF3Si). Due to the large shear force provided by

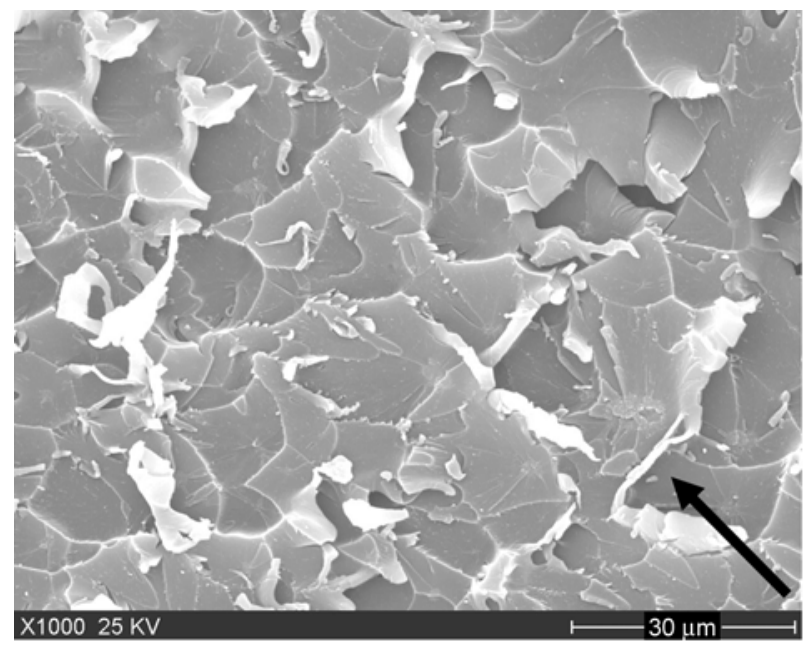

a)

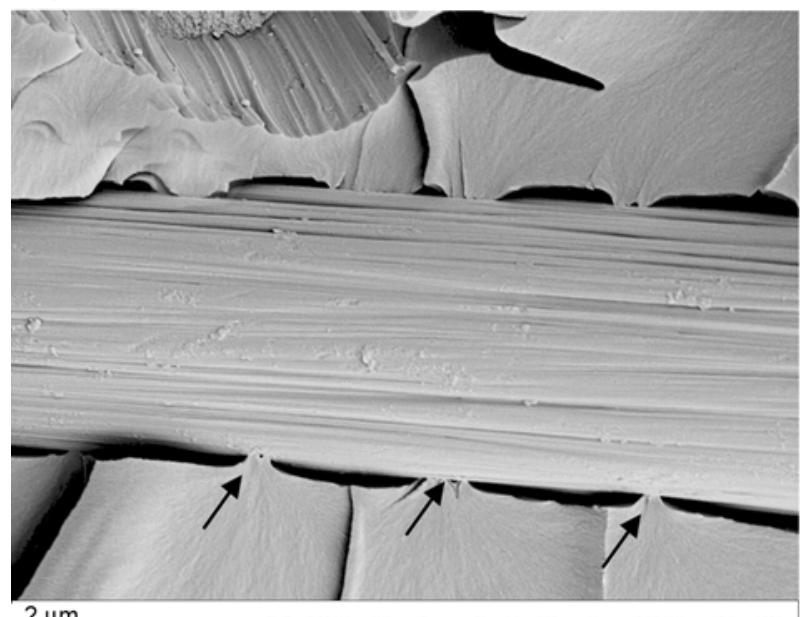

$2 \mu \mathrm{m}$

c)

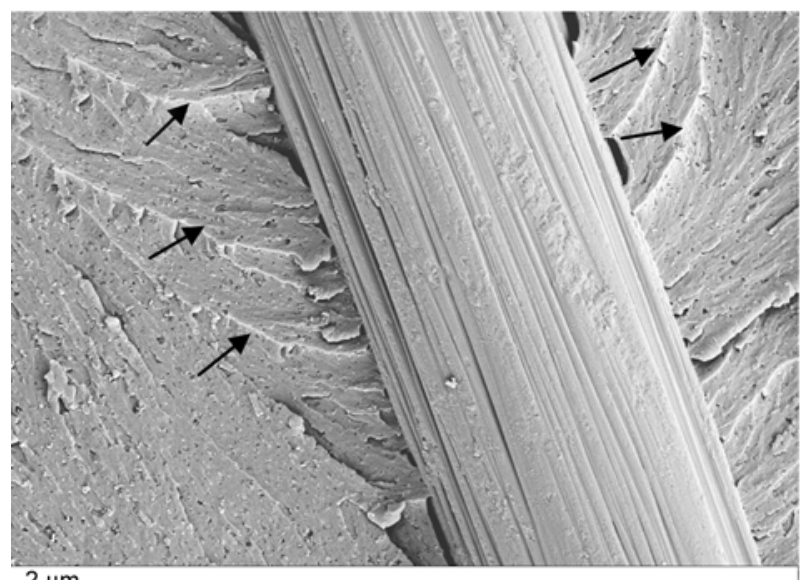

$2 \mu \mathrm{m}$

EHT $=3.00 \mathrm{kV}$ WO $=14 \mathrm{~mm}$ Signal A-SE2 Mag= $15.00 \mathrm{KX} \quad 15 \mathrm{Dec} 2009$

e) the dissolver, the nanoparticles were homogeneously distributed into the epoxy matrix although small agglomerates remain present in the matrix. Typically, the size of the small agglomerates is less than $100 \mathrm{~nm}$, with some exceptions which are in submicron scales (cf. Figure 2e and Figure 2f). Comparing the fracture surfaces of the $10 \mathrm{CF} 3 \mathrm{Si}$ and $10 \mathrm{CF}$

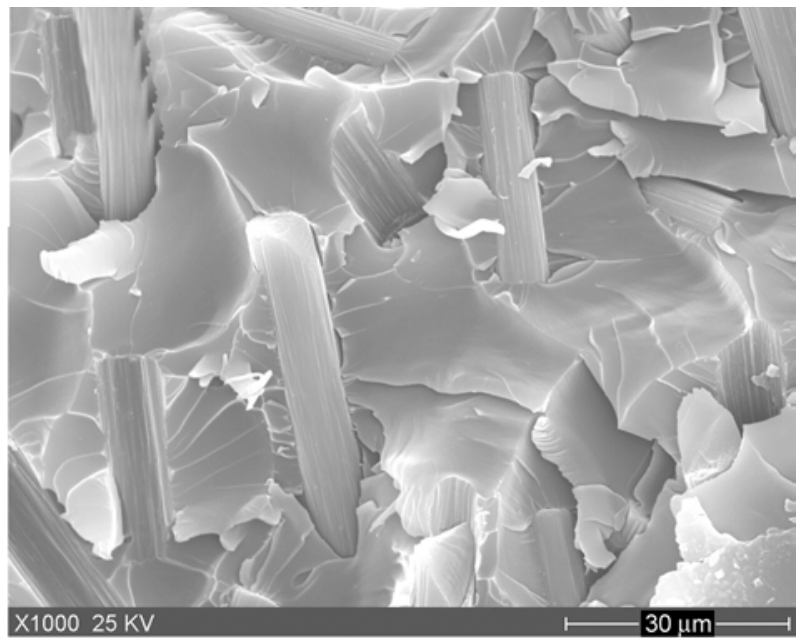

b)

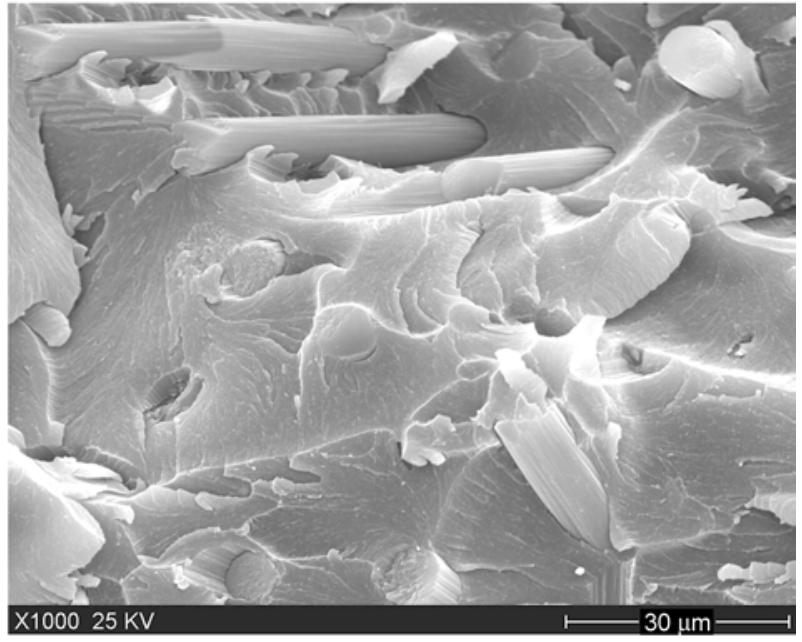

d)

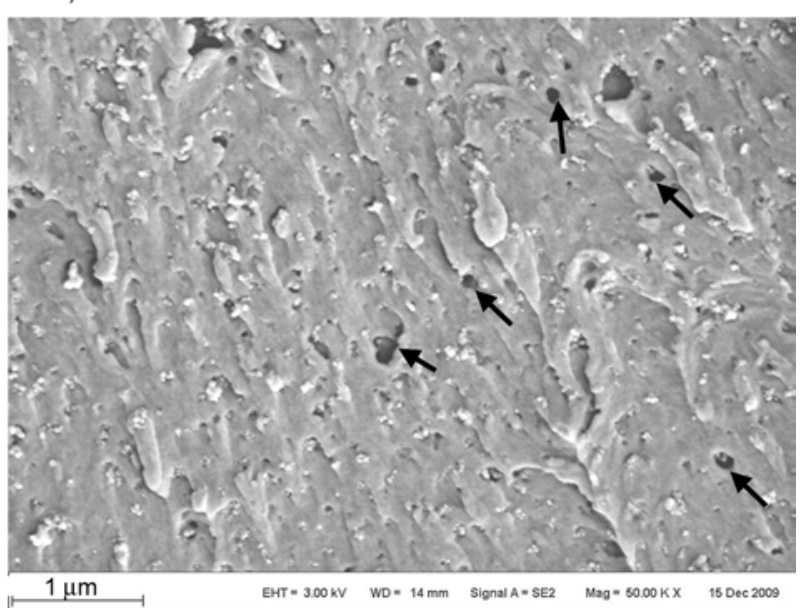

f)

Figure 2. Fracture surfaces taken from tensile specimens $1 \mathrm{Si}(\mathrm{a}), 10 \mathrm{CF}(\mathrm{b})$ and (c), 10CF3Si (d), (e) and (f) 
(Figure 2d and Figure 2b), two features are clear. First, the fiber-matrix interface of the multiscale composite is far less damaged than in the SCF composite. Second, extensive plastic deformations and numerous microcracks can be resolved in the matrix of the multiscale composites. Some of the microcracks are indicated in Figure 2e by arrows. These microcracks were produced in the particle-particle ligaments and the particle-SCF ligaments due to the cavitation and debonding of nanoparticles. Figure $2 \mathrm{f}$ displays a local zone on the fracture surface of the multiscale composite at high magnification. It is clear that debonding of nanoparticles takes place. Significant matrix plastic dilatation, indicated by arrow in Figure 2f, can be found around the debonded nanoparticles. The obvious plastic dilatation of epoxy matrix is believed to form due to the cavitation of nanoparticles [4, 51, 52]. Nanoparticles first cavitate and induce crack bifurcation and pinning. As a result, before the onset of a critical crack numerous microcracks are produced. This triggers extensive shear yielding of the matrix (cf. Figure 2f). It is worth of noting that the supposed core-shell like structure of the nanoparticles strongly favors the cavitation. The sub-critical microcracks and the debonding of the nanoparticles are assumed to be the major mechanisms for the enhanced 'strainsoftening' of the multiscale composite at a high strain.

According to the rule of mixture, the enhanced matrix stiffness due to the presence of nanoparticles will enhance the modulus of the multiscale composites, compared to the composites filled solely with SCFs. If we predict the modulus of the multiscale

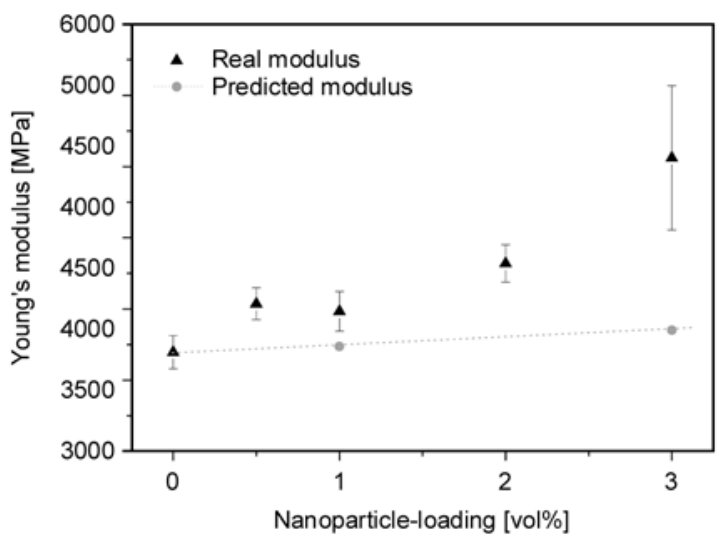

Figure 3. Difference between the real moduli of the hybrid composites and the predicted values using the mixture rule composites using the above mixture rule, the related moduli are only slightly higher than the conventional composite (10CF, cf. Figure 3). Comparing the predicted and experimental moduli, one can notice that the moduli of the multiscale composites are much higher than those predicted by the rule of mixture (cf. Figure 3). This suggests that the contribution of the nanoparticles on the modulus of the multiscale composites is much higher than predicted by additivity rule.

During loading of the composites filled only with SCFs large local stresses develop in the matrix close to the fiber ends owing to stress concentration effects, and as a result larger local strains are signified in these regions $[13,15,46]$. The neighboring SCF are 'too far' in the brittle matrix, and thus they can hardly participate in the stress relief needed to avoid catastrophic fracture $[13,15,46]$. The scenario is different in the multiscale composites. The broken tensile specimens were polished in order to study with an optic microscope the morphologies under the fracture planes. Figure 4 illustrate the polished section of 10CF3Si. The diagram associated with Figure 4 shows the location from which observations were made. For the microcomposite, e.g. $10 \mathrm{CF}$, no obvious cracking is noticed under the fracture plane [34]. However, multiple matrix cracks are observed under the fracture plane of the multiscale composite (the multiple cracking becomes less sharp on the graph due to the polishing). The multiple matrix cracks are also observed in case of the multiscale composites reinforced by combined SCFs and CNFs [34]. The formation of the multiple cracks gives hints that the stress field in the matrix between SCFs is homogenized with the presence of nanoparticles. This is due to the fact in the matrix in between the SCFs now well distributed nanoparticles are present which work for an efficient stress transfer and redistribution. Stress concentrations are relieved via cavitation of the nanoparticles making the matrix becomes more ductile. This is helpful in respect of the neighboring SCF which now can fulfill their reinforcing role accordingly. The outcome is a strongly enhanced strength as less stress concentration-induced premature failure occurs, which was found in fact (cf. Figure 1d). This failure sequence can also explain the observed changes in the fiber-matrix interfacial failure (cf. Figures $2 \mathrm{c}$ and $2 \mathrm{e}$ ). 

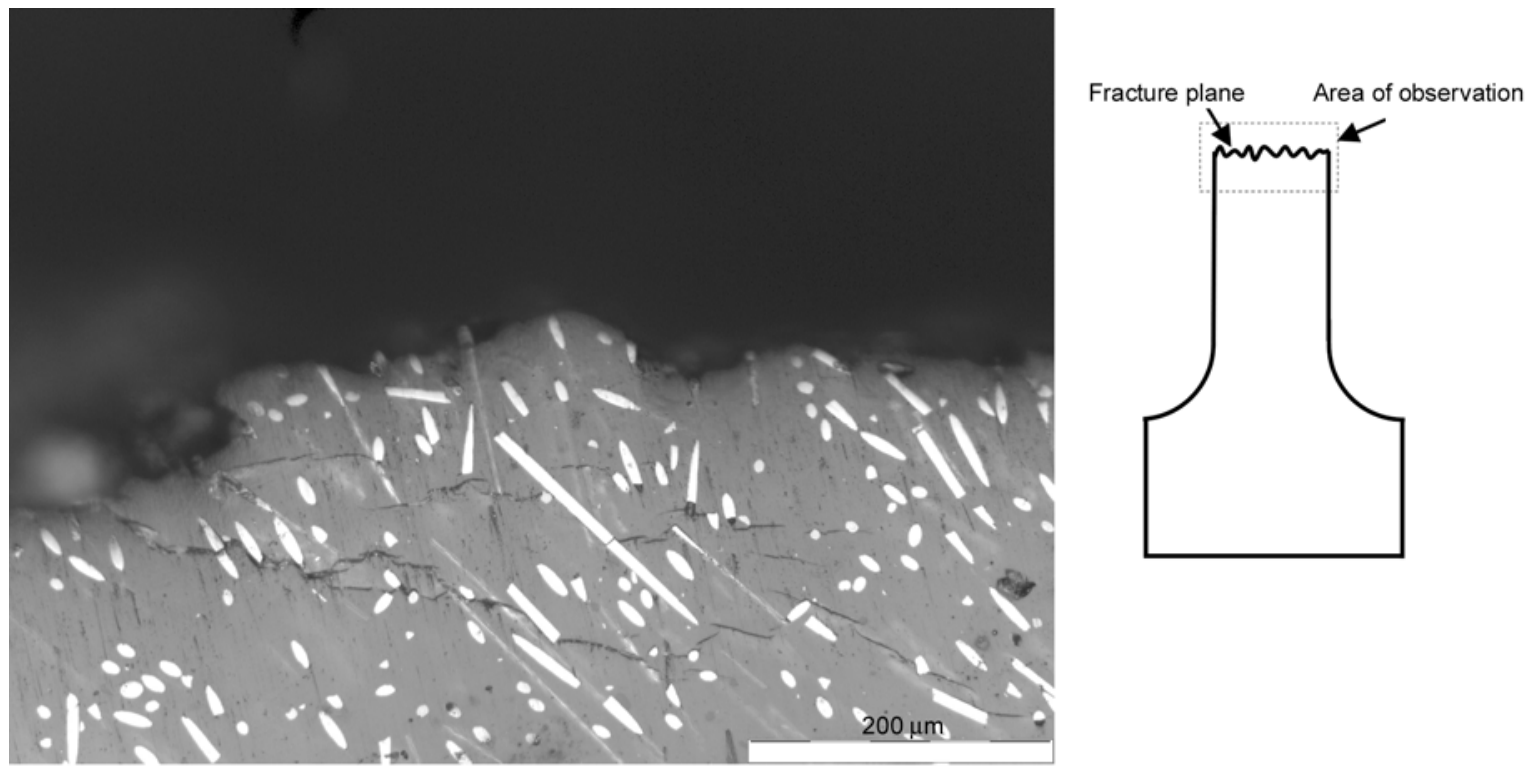

a)

b)

Figure 4. Optic micrographs of polished sections, perpendicular and near to the fracture planes (a), of 10CF3Si; the diagram associated shows the location observed (b)

For the composites filled only with SCFs the extra stress in the regions adjacent to a fiber end is associated with large local strain. The stress homogenization of the matrix due to the presence of nanoparticles enhances not only the $E$-modulus (Figure 1c), but also the ductility (elongation at break) of the multiscale composites. The data in Figure 1e indicates, however, remained or slightly enhanced ductility. The reason behind is the multiple microracking (cf. Figure 4) which is accompanied with an inherently small change in the elongation at break. Nevertheless, the multiple matrix cracking in Figure 4 evidence the stress relief proposed.

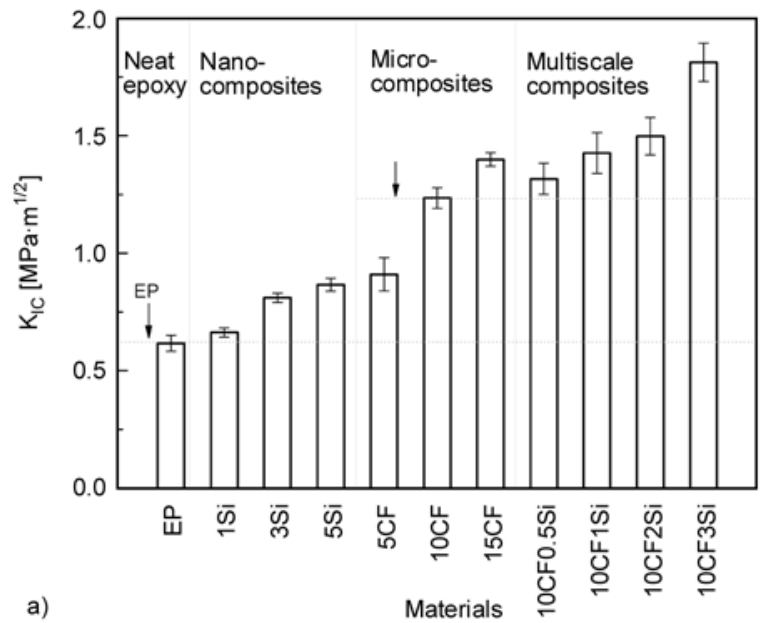

\subsection{Fracture toughness}

Figure $5 \mathrm{a}$ and Figure $5 \mathrm{~b}$ show the fracture toughness, $K_{\mathrm{IC}}$, and the critical energy release rate, $G_{\mathrm{IC}}$, of the materials studied. The fracture toughness of the pure EP was $0.62 \mathrm{MPa} \cdot \mathrm{m}^{1 / 2}$ (cf. Figure 5a). The nanoparticles enhance the fracture toughness which increases monotonously with increasing nanoparticle concentration from 1.0 to $5.0 \mathrm{vol} \%$. At $5.0 \mathrm{vol} \%$ nanoparticles content, the fracture toughness was increased by about $40 \%$. With 5 vol $\%$ SCFs, the fracture toughness is increased by $47 \%$. An increase in fiber-loading from 5 to $15 \mathrm{vol} \%$ leads to a steady increase in the fracture toughness. The addition of

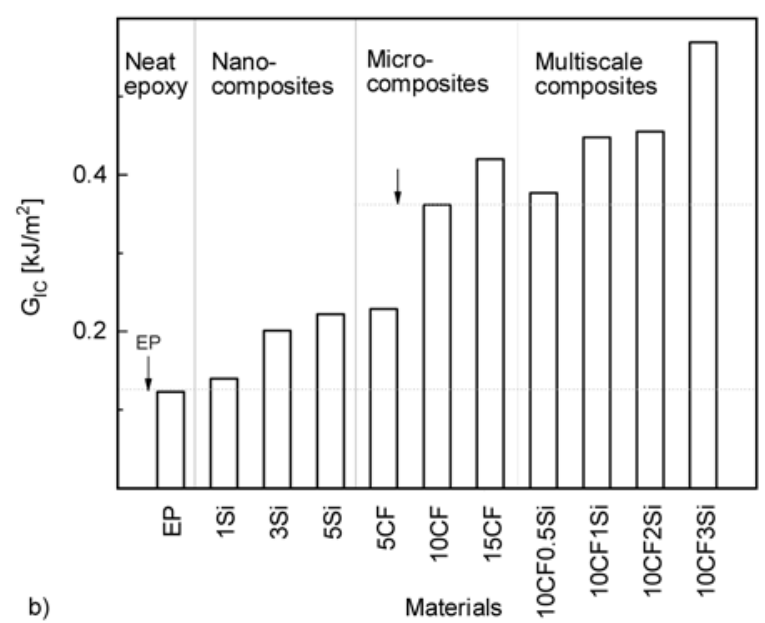

Figure 5. Fracture toughness, $K_{\mathrm{IC}}$, (a) and critical energy release rate, $G_{\mathrm{IC}}$, (b) of materials studied. Dash lines in (a) and (b) indicating the levels of two reference materials, i.e. pure epoxy and SCFs/EP, are added for easier comparisons. 
$10 \mathrm{vol} \% \mathrm{SCF}$ doubles the fracture toughness of the parent EP.

The multiscale composites present much higher fracture toughness than the corresponding microcomposite (10CF) and nanocomposites (1Si-3Si). It is interesting to note that the combination of nano$\mathrm{SiO}_{2}$ and SCF enhances the fracture toughness more than predicted by the additivity rule (cf. Figure $5 \mathrm{a}$ ). For example, the combination of $10 \mathrm{vol} \%$ $\mathrm{SCF}$ and 3 vol $\%$ nano- $\mathrm{SiO}_{2}$ increases the fracture toughness of the pure EP by about $194 \%$, while the superposition of the separate contributions of these two fillers, as respectively achieved in $3 \mathrm{Si}$ and $10 \mathrm{CF}$, would result in a value of $132 \%$. The tendency of $G_{\mathrm{IC}}$ is similar to that of $K_{\mathrm{IC}}$. Figure $5 \mathrm{~b}$ shows that both the nanoparticles and the SCFs increase the $G_{\text {IC }}$ of the EP. As to the multiscale composites with a nanoparticle concentration 1 to $3 \mathrm{vol} \%$, the combination of nano- $\mathrm{SiO}_{2}$ and $\mathrm{SCF}$ leads to an improvement in $G_{\mathrm{IC}}$ which is significantly higher than the predicted one based on the rule of additivity.

Figure 6a shows the typical fracture surface of the nanocomposite filled with nano- $\mathrm{SiO}_{2}(3 \mathrm{Si})$. The fracture propagation direction is downward as indicated by an arrow, which is identical to all the other CT fracture surfaces presented in this paper. Numerous ribs can be detected on the fracture surface. Note that the fracture surface of pure epoxy is very smooth without hints for significant plastic deformation [34]. These ribs are formed when the cracks moving in slightly different planes coalesce, and they are believed to contribute to toughness improvement $[4,27]$. Figure $6 b$ illustrates the fracture surface of $3 \mathrm{Si}$ near the crack tip at high magnification. The nanoparticles cavitate and debond from the matrix and they induce crack bifurcation and pinning. As results of the cavitation and crack pinning, two or more fracture planes are produced. This is helpful for the matrix to dissipate energy by shear yielding, the onset of which is obvious by the ribs $[21,51$, 52].

Figure $6 \mathrm{c}$ shows the CT fracture surface of $10 \mathrm{CF}$. When plane strain conditions prevail, the typical crack path in short fiber reinforced composites is of zig-zag type, as was intensively analyzed by KargerKocsis and Friedrich [13-16]. Three major failure mechanisms dominate the fracture behavior of conventional composites filled with short fibers:
1. Pull-out and fracture of fibers, lying more or less perpendicular to the crack front;

2. Fiber/matrix debonding of fibers aligned more parallel to the fracture plane;

3. Stress concentration on fiber ends, followed by brittle fracture of the epoxy matrix;

All these events happen in a limited plastic zone (or termed damage zone).

Figure 6d displays a typical fracture surface of the multiscale composites (10CF3Si). Pull-out, fracture of fibers, and fiber/matrix debonding are also clearly observable on the fracture surface. Figure 6e and Figure $6 f$ show the fracture surfaces at higher magnifications. Compared to the SCF-EP composites, the matrix fails less brittlely in case of the multiscale composites. Extensive micro-mechanical deformations of the matrix are clearly noticed in Figure $6 \mathrm{~d}$ to Figure $6 \mathrm{f}$. Similar to the nancomposites, the nanoparticles in front of the crack tip cavitate, debond, cause crack bifurcation, crack pinning and microcracks. By this way the nanoparticles can relieve the overstress on fiber ends in the vicinity of the crack tip. As consequence, compared to the conventional composite (10CF) [34], a larger plastic zone develops in which other SCFs can participate in the stress transfer (in case of multiscale composites), as schematically illustrated in Figure 7. Surely, this leads to enhancements in $K_{\mathrm{IC}}$ and $G_{\mathrm{IC}}$, compared with SCFs-filled epoxy. Therefore, the contribution of the nanoparticles is twofold. First, they improve the fracture toughness triggering such mechanisms as cavitation, crack bifurcation and pinning etc. Second, they can relieve the overload near to the fiber ends in front of the crack tip via the above matrix-related failure events. The overall outcome is an enlarged plastic zone which is assumed to be the key factor for the synergisms reported.

As aforementioned, applaudable improvements in mechanical and fracture properties are also achieved in our recent work with combining SCFs with CNFs [34]. Basing on these works, it is assumed that the distinctly different dimensions of the combined fillers are the key factor for their synergetic roles. In the multiscale composite system, the nano-sized fillers can protect the micro-sized fillers by release stress concentration occurring near the microfillers. In comparison to nanoparticles, it seems that the 


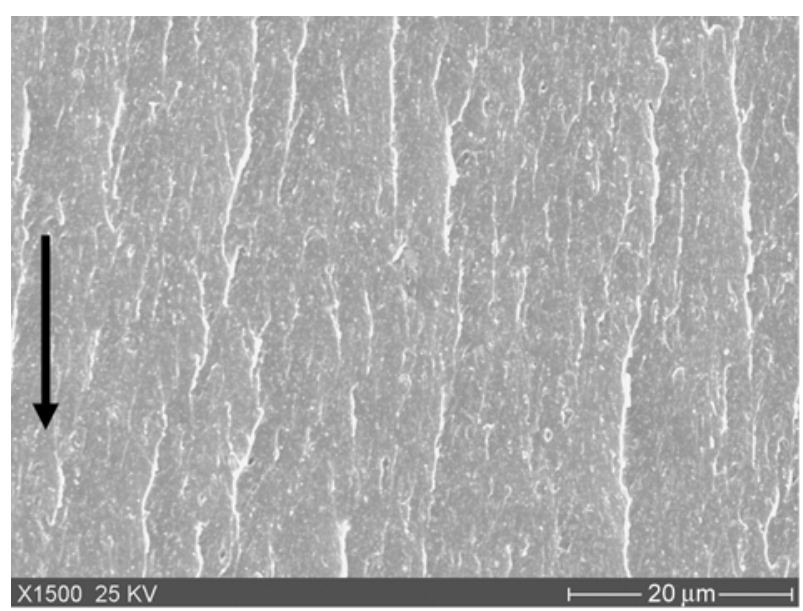

a)

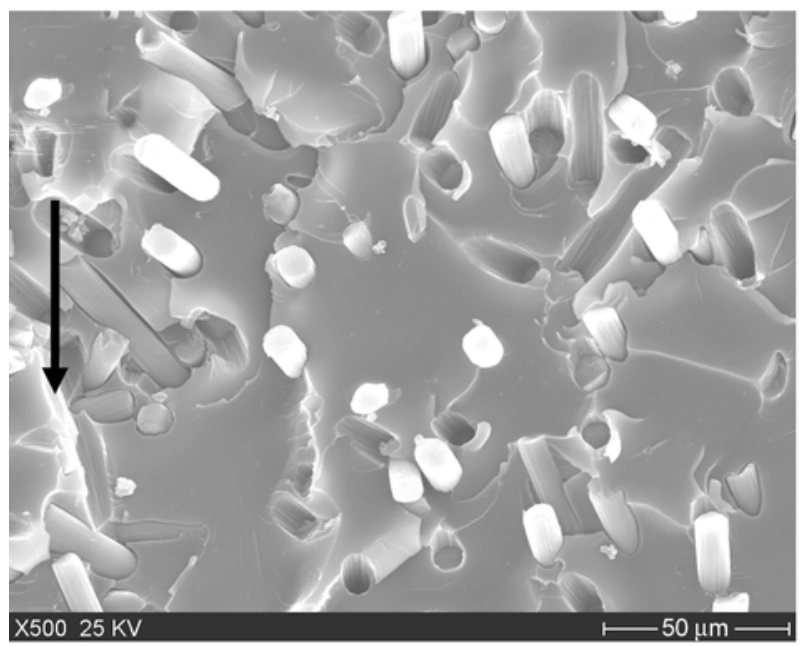

c)

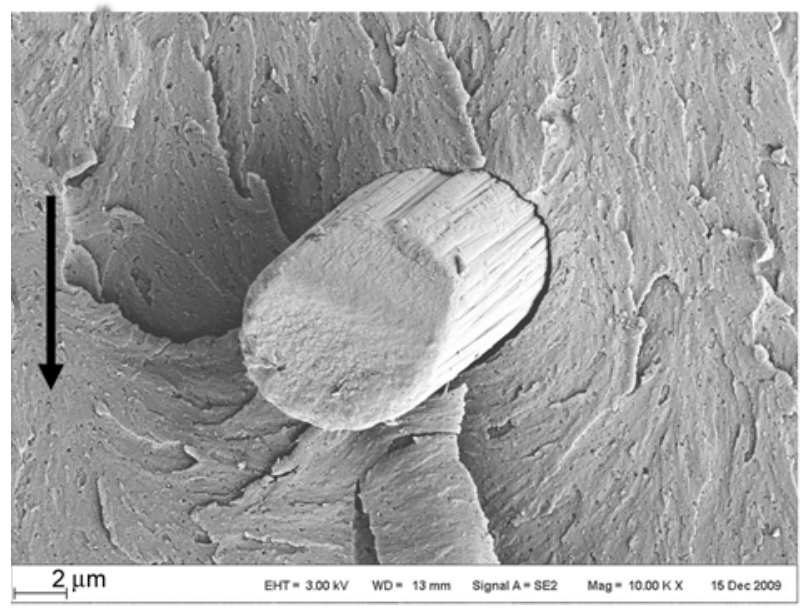

e)

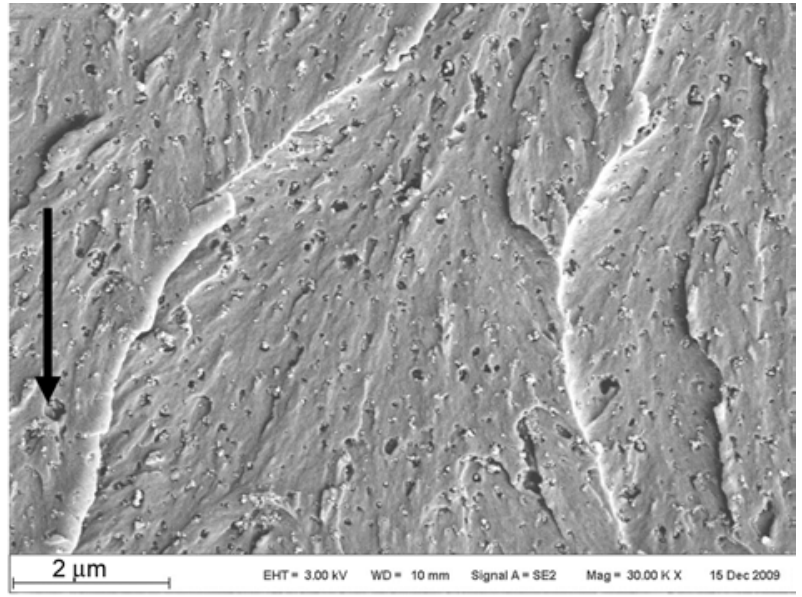

b)

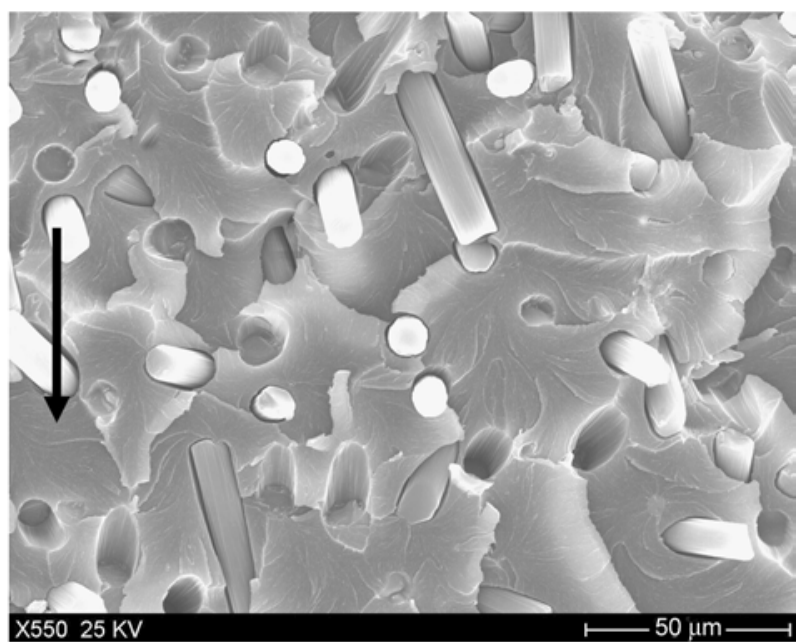

d)

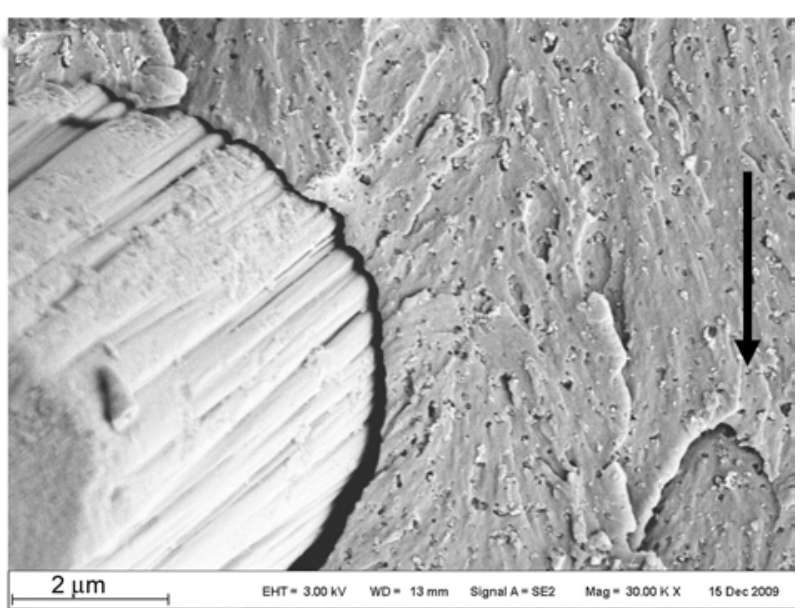

f)

Figure 6. Fracture surfaces taken from CT tests of $3 \mathrm{Si}$ (a) and (b), 10CF (c), 10CF3Si (d), (e) and (f)

efficiency of CNFs is more efficient on improving the mechanical and fracture properties. That is, less $\mathrm{CNF}$ fraction is required for improving the SCFsEP properties to the same extent as realized by nanoparticles. This can be related to the high aspect ratios of CNFs, which may lead to a more efficient stress transfer. 


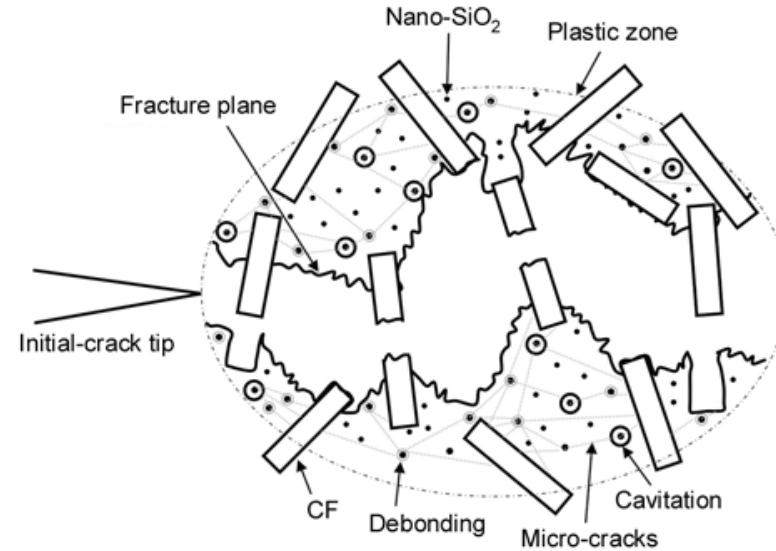

Figure 7. Schematic of plain-strain failure modes proposed for epoxy composites filled with SCFs and nanoparticles. The sizes of the fillers were not depicted in proportion

\section{Conclusions}

In the present work, mechanical and fracture properties of three series of epoxy composites were compared. The three series of composites are respectively I: microcomposites filled with micron SCFs ranging from 5 to $15 \mathrm{vol} \%$, II: nanocomposites filled with silica nanoparticles up to 5 vol\% and III: multiscale composites filled with the both fillers. Incorporation of multiscale fillers was associated with synergetic effects in respect to the tensile ( $E$-modulus, strength) and fracture properties $\left(K_{\mathrm{IC}}\right.$ and $\left.G_{\mathrm{IC}}\right)$ of EP resin. Based on this work the following conclusions can be drawn:

1. Filled with nanosilica particles in low concentration range, the modulus of EP can only be slightly increased and the tensile strength is slightly increased or remained. The nanoparticles increase moderately the fracture toughness of epoxy. Filled with microsized SCFs, the modulus of epoxy is highly improved, however at cost of the elongation rate which is dramatically reduced. The tensile strength is remained or slightly reduced. The fracture toughness is improved with increasing the SCF fraction up to 15 vol\%. With a SCF loading higher than $10 \mathrm{vol} \%$, the fracture toughness of the EP can be almost doubled.

2. The combination of the multiscale fillers leads to a significant synergism in both of the tensile and fracture mechanical responses of the EP. The contributions of the combined fillers to the $E$-modulus, tensile strength, fracture toughness and fracture energy are markedly higher than those expected by the additivity rule considering the separate contributions of the respective fillers. The nanoparticles cavitate, induce crack bifurcation and crack pinning. Shear yielding of matrix and microcracks near SCFs take place. By this way, stress concentration near fibers, especially fiber ends, is efficiently relieved. As consequence, a larger plastic zone develops in presence of both nano- $\left(\mathrm{SiO}_{2}\right)$ and microfillers (SCF) than solely in the SCF-reinforced EP. This is believed to be the major reason for the synergetic effects observed for the EP with multiscale fillers.

\section{Acknowledgements}

This work is connected to the scientific program of the 'Development of quality-oriented and harmonized $\mathrm{R}+\mathrm{D}+\mathrm{I}$ strategy and functional model at BME' project. This project is supported by the New Széchenyi Plan (Project ID: TÁMOP-4.2.1/B-09/1/KMR-2010-0002).

\section{References}

[1] Teh S. F., Liu T., Wang L., He C.: Fracture behaviour of poly(ethylene terephthalate) fiber toughened epoxy composites. Composites Part A: Applied Science and Manufacturing, 36, 1167-1173 (2005). DOI: $10.1016 /$ j.compositesa.2004.08.007

[2] Sue H-J.: Craze-like damage in a core-shell rubbermodified epoxy system. Journal of Materials Science, 27, 3098-3107 (1992).

DOI: $10.1007 / \mathrm{BF} 01154125$

[3] Bagheri R., Pearson R. A.: Role of particle cavitation in rubber-toughened epoxies: 1. Microvoid toughening. Polymer, 37, 4529-4538 (1996). DOI: 10.1016/0032-3861(96)00295-9

[4] Karger-Kocsis J., Friedrich K.: Microstructure-related fracture toughness and fatigue crack growth behaviour in toughened, anhydride-cured epoxy resins. Composites Science and Technology, 48, 263-272 (1993). DOI: 10.1016/0266-3538(93)90143-5

[5] Nguyen F. N., Berg J. C.: Novel core-shell (dendrimer) epoxy tougheners: Processing and hot-wet performance. Composites Part A: Applied Science and Manufacturing, 39, 1007-1011 (2008).

DOI: $10.1016 /$ j.compositesa.2008.03.005

[6] Cardwell B. J., Yee A. F.: Toughening of epoxies through thermoplastic crack bridging. Journal of Materials Science, 33, 5473-5484 (1998). DOI: 10.1023/A:1004427123388

[7] Lee J., Yee A. F.: Fracture behavior of glass bead filled epoxies: Cleaning process of glass beads. Journal of Applied Polymer Science, 79, 1371-1383 (2001). DOI: $10.1002 / 1097-4628(20010222) 79: 8<1371:: A I D-$ APP40>3.0.CO;2-O 
[8] Lee J., Yee A. F.: Inorganic particle toughening I: Micro-mechanical deformations in the fracture of glass bead filled epoxies. Polymer, 42, 577-588 (2001). DOI: 10.1016/S0032-3861(00)00397-9

[9] Lee J., Yee A. F.: Inorganic particle toughening II: Toughening mechanisms of glass bead filled epoxies. Polymer, 42, 589-597 (2001). DOI: 10.1016/S0032-3861(00)00398-0

[10] Adachi T., Osaki M., Araki W., Kwon S-C.: Fracture toughness of nano- and micro-spherical silica-particlefilled epoxy composites. Acta Materialia, 56, 21012109 (2008). DOI: $10.1016 /$ j.actamat.2008.01.002

[11] Sanadi A. R., Piggott M. R.: Interfacial effects in carbon-epoxies. Part 3. Toughness with short fibres. Journal of Materials Science, 21, 1642-1646 (1986).

DOI: $10.1007 / \mathrm{BF} 01114720$

[12] Piggott M. R.: The effect of aspect ratio on toughness in composites. Journal of Materials Science, 9, 494502 (1974).

DOI: $10.1007 / \mathrm{BF} 00737854$

[13] Karger-Kocsis J.: Instrumented impact fracture and related failure behavior in short- and long-glass-fiberreinforced polypropylene. Composites Science and Technology, 48, 273-283 (1993).

DOI: 10.1016/0266-3538(93)90144-6

[14] Karger-Kocsis J.: Structure and fracture mechanics of injection-molded composites. in 'International encyclopedia of composites' (ed.: Lee S.M.) VCII Publishers, New York, Vol 5, 337-356 (1991).

[15] Karger-Kocsis J., Friedrich K.: Microstructural details and the effect of testing conditions on the fracture toughness of injection-moulded poly(phenylene-sulphide) composites. Journal of Materials Science, 22, 947-961 (1987).

DOI: $10.1007 / \mathrm{BF} 01103535$

[16] Friedrich K.: Microstructural efficiency and fracture toughness of short fiber/thermoplastic matrix composites. Composites Science and Technology, 22, 43-74 (1985). DOI: 10.1016/0266-3538(85)90090-9

[17] Farber K. T., Evans A. G.: Crack deflection process-I. Theory. Acta Metallurgica, 31, 565-576 (1983). DOI: 10.1016/0001-6160(83)90046-9

[18] Farber K. T., Evans A. G.: Crack deflection process-II. Experiment. Acta Metallurgica, 31, 577-584 (1983). DOI: 10.1016/0001-6160(83)90047-0

[19] Lange F. F.: The interaction of a crack front with a second-phase dispersion. Philosophical Magazine, 22, 983-992 (1970).

DOI: $10.1080 / 14786437008221068$

[20] Green D. J., Nicholson P. S., Embury J. D.: Fracture of a brittle particulate composite. Part 2. Theoretical aspects. Journal of Materials Science, 14, 1657-1661 (1979).

DOI: $10.1007 / \mathrm{BF} 00569287$
[21] Wetzel B., Rosso P., Haupert F., Friedrich K.: Epoxy nanocomposites - Fracture and toughening mechanisms. Engineering Fracture Mechanics, 73, 23752398 (2006).

DOI: $10.1016 /$ j.engfracmech.2006.05.018

[22] Wetzel B., Haupert F., Zhang M. Q.: Epoxy nanocomposites with high mechanical and tribological performance. Composites Science and Technology, 63, 2055-2067 (2003).

DOI: $10.1016 / \mathrm{S} 0266-3538(03) 00115-5$

[23] Sanadi A. R., Piggott M. R.: Interfacial effects in carbon-epoxies. Part 1. Strength and modulus with short aligned fibres. Journal of Materials Science, 20, 421430 (1985).

DOI: $10.1007 / \mathrm{BF} 01026510$

[24] Zhang H., Tang L-C., Zhang Z., Friedrich K., Sprenger S.: Fracture behaviours of in situ silica nanoparticlefilled epoxy at different temperatures. Polymer, 49, 3816-3825 (2008).

DOI: $10.1016 /$ j.polymer.2008.06.040

[25] Ma J., Mo M-S., Du X-S., Rosso P., Friedrich K., Kuan H-C.: Effect of inorganic nanoparticles on mechanical property, fracture toughness and toughening mechanism of two epoxy systems. Polymer, 49, 3510-3523 (2008).

DOI: 10.1016/j.polymer.2008.05.043

[26] Zhang H., Zhang Z., Friedrich K., Eger C.: Property improvements of in situ epoxy nanocomposites with reduced interparticle distance at high nanosilica content. Acta Materialia, 54, 1833-1842 (2006).

DOI: 10.1016/j.actamat.2005.12.009

[27] Rosso P., Ye L., Friedrich K., Sprenger S.: A toughened epoxy resin by silica nanoparticle reinforcement. Journal of Applied Polymer Science, 100, 1849-1855 (2006). DOI: 10.1002/app.22805

[28] Johnsen B. B., Kinloch A. J., Mohammed R. D., Taylor A. C., Sprenger S.: Toughening mechanisms of nanoparticle-modified epoxy polymers. Polymer, 48, 530-541 (2007). DOI: $10.1016 /$ j.polymer.2006.11.038

[29] Uddin M. F., Sun C. T.: Strength of unidirectional glass/ epoxy composite with silica nanoparticle-enhanced matrix. Composites Science and Technology, 68, 16371643 (2008). DOI: 10.1016/j.compscitech.2008.02.026

[30] Manjunatha C. M., Taylor A. C., Kinloch A. J., Sprenger S.: The tensile fatigue behaviour of a silica nanoparticle-modified glass fibre reinforced epoxy composite. Composites Science and Technology, 70, 193-199 (2010). DOI: 10.1016/j.compscitech.2009.10.012

[31] Qiu J., Zhang C., Wang B., Liang R.: Carbon nanotube integrated multifunctional multiscale composites. Nanotechnology, 18, 275708/1-275708/11 (2007).

DOI: $10.1088 / 0957-4484 / 18 / 27 / 275708$ 
[32] Karapappas P., Vavouliotis A., Tsotra P., Kostoppoulos V., Paipetis A.: Enhanced fracture properties of carbon reinforced composites by the addition of multi-wall carbon nanotubes. Journal of Composite Materials, 43, 977-985 (2009).

DOI: $10.1177 / 0021998308097735$

[33] Yokozeki T., Iwahori Y., Ishibashi M., Yanagisawa T., Imai K., Arai M., Takahashi T., Enomoto K.: Fracture toughness improvement of CFRP laminates by dispersion of cup-stacked carbon nanotubes. Composites Science and Technology, 69, 2268-2273 (2009). DOI: 10.1016/j.compscitech.2008.12.017

[34] Zhang G., Karger-Kocsis J., Zou J.: Synergetic effect of carbon nanofibers and short carbon fibers on the mechanical and fracture properties of epoxy resin. Carbon, 48, 4289-4300 (2010). DOI: $10.1016 / \mathrm{j}$.carbon.2010.07.040

[35] Allaoui A., Bounia N. E.: How carbon nanotubes affect the cure kinetics and glass transition temperature of their epoxy composites? - A review. Express Polymer Letters, 3, 588-594 (2009).

DOI: $10.3144 /$ expresspolymlett.2009.73

[36] Vassileva E., Friedrich K.: Epoxy/alumina nanoparticle composites. I. Dynamic mechanical behavior. Journal of Applied Polymer Science, 89, 3774-3785 (2003). DOI: 10.1002/app.12463

[37] Huang G. C., Lee J. K.: Isothermal cure characterization of fumed silica/epoxy nanocomposites: The glass transition temperature and conversion. Composites Part A: Applied Science and Manufacturing, 41, 473479 (2010).

DOI: 10.1016/j.compositesa.2009.12.003

[38] Ragosta G., Abbate M., Musto P., Scarinzi G., Mascia L.: Epoxy-silica particulate nanocomposites: Chemical interactions, reinforcement and fracture toughness. Polymer, 46, 10506-10516 (2005).

DOI: $10.1016 /$ j.polymer.2005.08.028

[39] Sun Y., Zhang Z., Moon K-S., Wong C. P.: Glass transition and relaxation behavior of epoxy nanocomposites. Journal of Polymer Science Part B: Polymer Physics, 42, 3849-3858 (2004).

DOI: $10.1002 /$ polb.20251

[40] Liu Y-L., Hsu C-Y., Wei W-L., Jeng R-J.: Preparation and thermal properties of epoxy-silica nanocomposites from nanoscale colloidal silica. Polymer, 44, 51595167 (2003).

DOI: 10.1016/S0032-3861(03)00519-6

[41] Becher O., Varley R., Simon G.: Morphology, thermal relaxations and mechanical properties of layered silicate nanocomposites based upon high-functionality epoxy resins. Polymer, 43, 4365-4373 (2002). DOI: $10.1016 / \mathrm{S} 0032-3861(02) 00269-0$
[42] Preghenella M., Pegoretti A., Migliaresi C.: Thermomechanical characterization of fumed silica-epoxy nanocomposites. Polymer, 46, 12065-12072 (2005). DOI: $10.1016 /$ j.polymer.2005.10.098

[43] Barrau S., Demont P., Maraval C., Bernes A., Lacabanne C.: Glass transition temperature depression at the percolation threshold in carbon nanotube-epoxy resin and polypyrrole-epoxy resin composites. Macromolecular Rapid Communications, 26, 390-394 (2005). DOI: $10.1002 /$ marc.200400515

[44] Meddad A., Fisa B.: Stress-strain behavior and tensile dilatometry of glass bead-filled polypropylene and polyamide 6. Journal of Applied Polymer Science, 64, 653-665 (1997).

DOI: 10.1002/(SICI)1097-4628(19970425)64:4<653:: AID-APP4>3.0.CO;2-M

[45] Sudár A., Móczó J., Vörös Gy., Pukánszky B.: The mechanism and kinetics of void formation and growth in particulate filled PE composites. Express Polymer Letters, 1, 763-772 (2007).

DOI: 10.3144/expresspolymlett.2007.105

[46] Sanadi A. R., Piggott M. R.: Interfacial effects in carbon-epoxies. Part 1. Strength and modulus with short aligned fibres. Journal of Materials Science, 20, 421430 (1985).

DOI: $10.1007 / \mathrm{BF} 01026510$

[47] Bowyer W. H., Bader M. G.: On the re-inforcement of thermoplastics by imperfectly aligned discontinuous fibres. Journal of Materials Science, 7, 1315-1321 (1972).

DOI: $10.1007 / \mathrm{BF} 00550698$

[48] Carman G. P., Reifsnider K. L.: Micromechanics of short-fiber composites. Composites Science and Technology, 43, 137-146 (1992). DOI: $10.1016 / 0266-3538(92) 90004-\mathrm{M}$

[49] Krenchel H.: Fibre reinforcement. Akademisk Forlag, Copenhagen (1964).

[50] Lin G. M., Lai J. K. L.: Fracture mechanism in short fibre reinforced thermoplastic resin composites. Journal of Materials Science, 28, 5240-5246 (1993). DOI: $10.1007 / \mathrm{BF} 00570071$

[51] Karger-Kocsis J., Friedrich K.: Fatigue crack propagation and related failure in modified, andhydride-cured epoxy resins. Colloid and Polymer Science, 270, 549562 (1992). DOI: $10.1007 / \mathrm{BF} 00658286$

[52] Sue H-J., Garcia Meitin E. I., Picklman D. M., Bott C. J.: Fracture mechanisms in rigid core-shell particle modified high performance epoxies. Colloid and Polymer Science, 274, 342-349 (1996).

DOI: $10.1007 / \mathrm{BF} 00654054$ 